\section{Electronic retinal implants and artificial vision: journey and present}

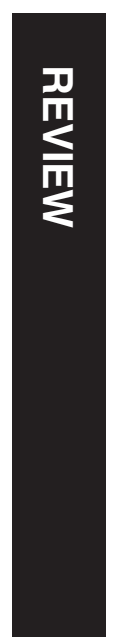

\begin{abstract}
Retinitis pigmentosa and age-related macular degeneration are two significant causes of severe visual dysfunction. In both, the retinal photoreceptors degenerate, preventing successful conversion of light into electrical energy that is interpreted in the visual cortex as visual function. Artificial vision or visual function began over two centuries ago with the idea of creating artificial light pulses, or phosphenes, through cortical stimulation. The pursuit is now on to improve artificial visual function. Two retinal implants appear the most likely to succeed in the future having undergone multicentre human trials: the Argus II electronic epiretinal device (Second Sight Medical Products, CA, USA) and Alpha-IMS electronic subretinal device (Retina Implant AG, Germany). The trial results to date are encouraging with visual improvement and acceptable safety profiles reported for both devices. At present, the visual function generated by either device does not offer high enough resolution or acuity for a patient to regain a fully functional life. Despite this, both devices not only have the potential, but have actually improved the vision-related quality of life in a significant number of patients implanted. With this in mind, the economic argument is clear. Provided device-life is long enough, its cost should be acceptable for the obtained improvement in the quality of life. The aim of this Review Article is to assist those readers that may be considering offering any of these devices as a treatment for blindness in Retinitis Pigmentosa.

Eye (2017) 31, 1383-1398; doi:10.1038/eye.2017.65; published online 26 May 2017
\end{abstract}

\section{Methodology}

In May 2016 we searched the Embase and Ovid Medline databases using the keywords retin\$ implant, retin\$ chip, retin\$ prosthesis, visual prosthes\$, artificial vision, Epi-Ret 3, Argus II, Alpha-IMS, Intelligent Medical Implants, Boston Retinal Implant and bionic eye.

The only limit applied was English language. There were no date limits. Articles judged to be of interest were included unless they did not contain any relevant information. We manually searched the reference lists of the studies included in the review for additional studies. We did not hand-search journals or conference proceedings.

\section{Introduction}

In 2010 the WHO estimated that 39 million people worldwide are blind. ${ }^{1}$ A small but significant percentage of these are unavoidable blinding conditions. These primarily include retinitis pigmentosa $(R P)$ and age-related macular degeneration (AMD). ${ }^{2}$ For centuries clinicians and researchers have been looking for methods to restore sight in individuals with these conditions. Several promising approaches have emerged, including gene therapy and electronic retinal implants. Gene therapy has recently been shown to be feasible and has improved vision in a trial at 3 years follow-up, albeit in a small patient subset with a specific leber congenital amaurosis (LCA) genotype. ${ }^{3}$

The focus of this review is artificial vision through electronic retinal implants. In simple terms, artificial vison is 'an experimental technique to make it possible for some blind people to see as a result of the electrical stimulation of the retina'. ${ }^{4}$ The idea of artificial vision began over two centuries ago in 1752 with the theorisations of the eminent Benjamin Franklin, who postulated to the Royal Society of London that sight and hearing could be restored with the use of electricity. ${ }^{5}$ Shortly after this in 1755 a French scientist by the name of Charles Leroy decided to investigate restoring sight to the blind, presumably after reading Benjamin
${ }^{1}$ Manchester Royal Eye Hospital, Manchester, UK

${ }^{2}$ Manchester Vision Regeneration (MVR) Lab at Manchester Royal Eye Hospital, NIHR/ Wellcome Trust Manchester CRF, Manchester Royal Eye Hospital, Manchester, UK

${ }^{3}$ Manchester Academic Health Science Centre and Centre for Ophthalmology and Vision Research, Institute of Human Development, University of Manchester, Manchester, UK

Correspondence: PE Stanga, Consultant Ophthalmologist \& Vitreoretinal Surgeon, Professor of Ophthalmology \& Retinal Regeneration, Manchester Royal Eye Hospital, Oxford Road, Manchester M13 9WL, UK

Tel: +44 (0)1612765580; Fax: +44 (0)1612765642. E-mail: retinaspecialist@ btinternet.com

Received: 9 October 2016 Accepted in revised form: 20 January 2017 Published online: 26 May 2017 
Franklin's theory. Figure 1 illustrates how he evoked visual disturbances in a blind volunteer using a wire wrapped around their head with current applied through it. $^{6}$ So began the long journey for the next 200 years towards realistic artificial vision devices.

Today two fundamentally different approaches exist in the pursuit of the ultimate bionic eye. An epiretinal approach, using an extraocular camera, processor and electrodes located on the ganglion cell side of the retina, and a subretinal approach using microelectrodes implanted between the retinal and retina pigment epithelium. ${ }^{7,8}$ The important work of Walter et al ${ }^{9}$ showed that a tack is surgically the best approach for attaching a retinal device.

\section{The early days}

The major significant breakthrough in artificial vision was not until the early 20th century. Foerster discovered it was possible to stimulate the visual pathway and produce 'pseudo' visual light signals, or phosphenes. In 1952, the phenomenon of phosphenes suddenly became understandable due to Hodgkin and Huxley's research. The scientific community for the first time was shown the exact nature of how electrical signals pass along nerves: depolarisation and action potentials. They finally demonstrated, illustrated in Figure 2, that electrical impulses along nerves were caused by inward movement of sodium ions and outward of potassium ions: known as depolarisation. ${ }^{10}$ Despite this surge in scientific understanding, the development of an implantable device in a human still seemed unlikely.

In 1968, Brindley and Lewin at Cambridge University performed arguably the most significant research in the early development of artificial vision. A 52-year-old blind man was implanted with a device, that consisted of a radio receiver array, connected to electrodes, implanted over the right occipital cortex. Miraculously, the previously blind patient experienced phosphenes in the left visual field and more importantly patterns could be created by adjusting parameters such as intensity and number of stimulating electrodes. With this experiment Brindley and Lewin showed the ophthalmic scientific community that electrical impulses could translate into useful vision for the blind and a functional device for everyday use could be created. In their own words 'Our findings strongly suggest that it will be possible, by improving our prototype, to make a useful prosthesis' ${ }^{11}$

As a consequence of this, many individuals were inspired to push forward against the challenges of device development. One such man, Dobelle, who likened the quest for artificial vision as a mountain summit attempt, so close but yet so far, spent the best part of the next three decades working with colleagues who believed in the

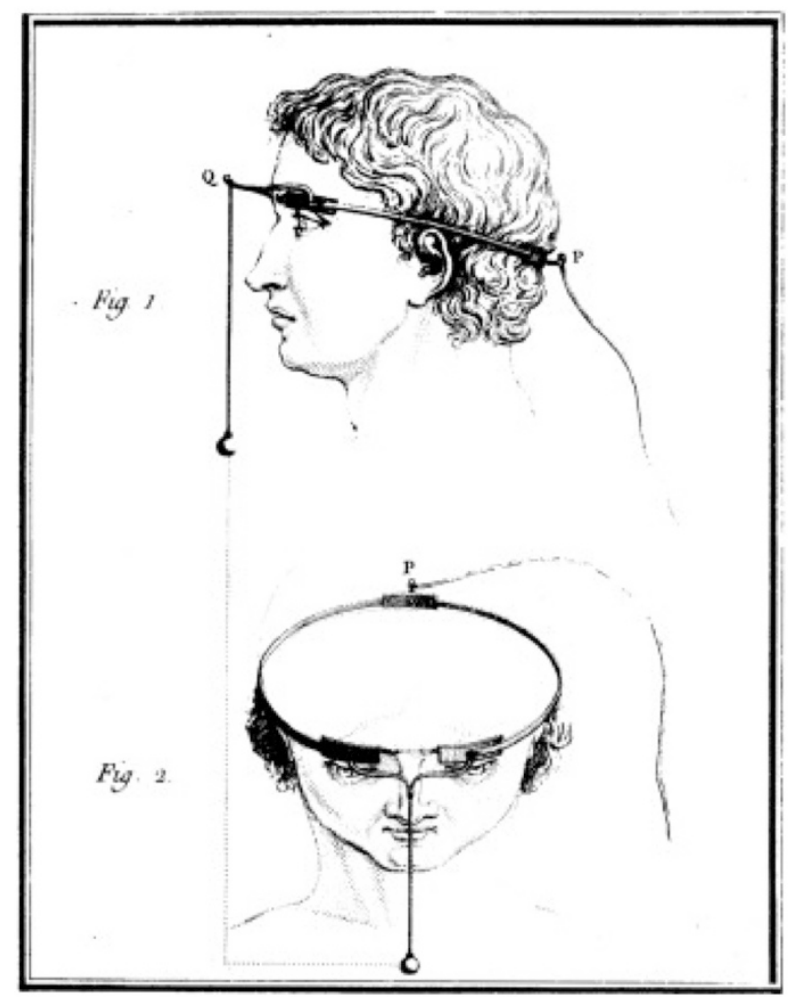

Figure 1 Method used by Charles Leroy in 1755 to evoke visual disturbances in a blind volunteer. A wire was wrapped around the patient's head with current applied through it.

possibility that a usable device could be created. They worked on factors that still vex us today: electrodes, processing, power supply and surgical implantation. ${ }^{12}$ Their hard work had humble beginnings, starting with the stimulation of the visual cortex of hemianopic patients during neurovascular operations shown in Figure 3.

Through this Dobelle and his team showed that electrical impulses did indeed produce phosphenes, concurring with Brindley and Lewin's and other previous research, but fundamentally it lacked the subjective experiences that only blind patients would give. ${ }^{13}$ This became known as a cortical implant, and although not the subject of this review is useful for context. Therefore, in 1976 Dobelle and his team published data on a permanent implant in a blind volunteer who was able to read braille using cortically generated phosphenes at 30 letters per minute. ${ }^{14}$

At the end of the 20th century scientists knew that for artificial vision devices to work, retinal cells would need to be in a functional state, which was contrary to the highly variable reports of cell loss in animal models. ${ }^{15}$ Advancements in imaging finally allowed the investigation of the pathological processes involved in RP and AMD. It was not until the 1990s that Humayun, Greenberg and De Juan et al conducted game changing research that enhanced our fundamental understanding of these two retinal diseases that result in nearly complete 


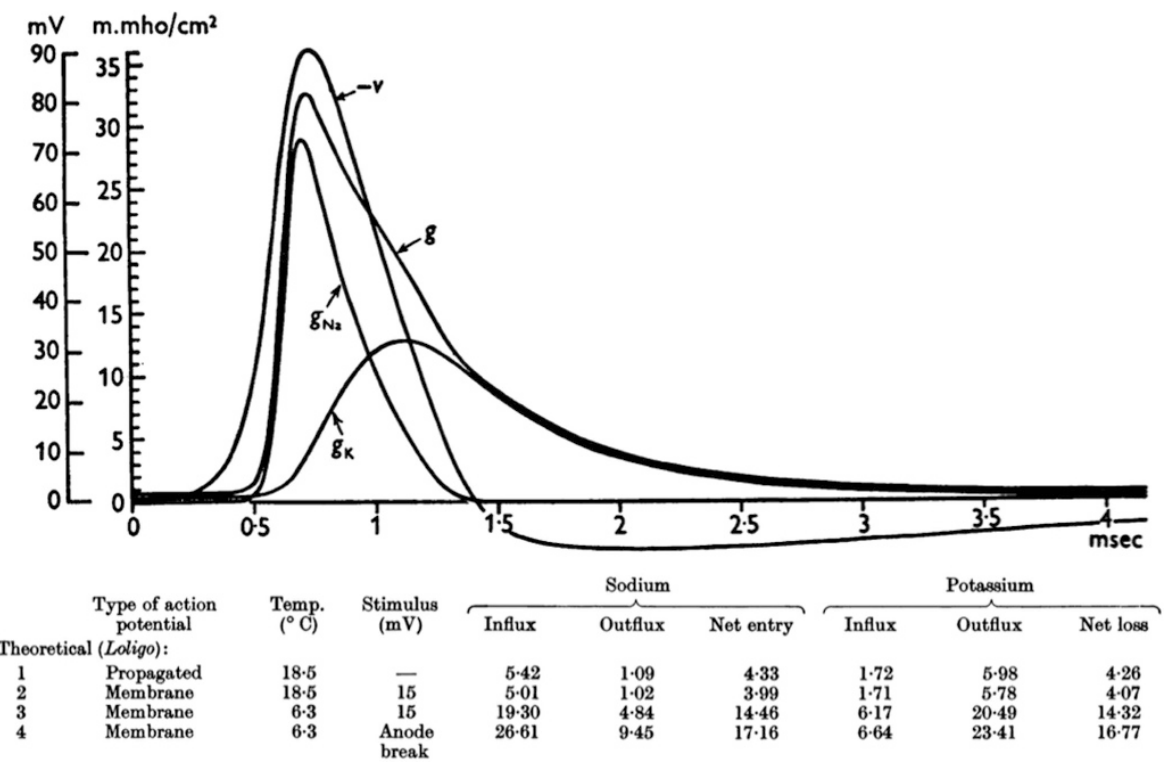

Figure 2 Summary of Hogkin and Huxley's proof of the existence of action potentials through ion movement. The conductance (g) of $\mathrm{Na}$ and $\mathrm{K}$ ions changes through an action potential with the net gain of $\mathrm{Na}$ ions and net loss of $\mathrm{K}$ ions producing voltage changes across a membrane.

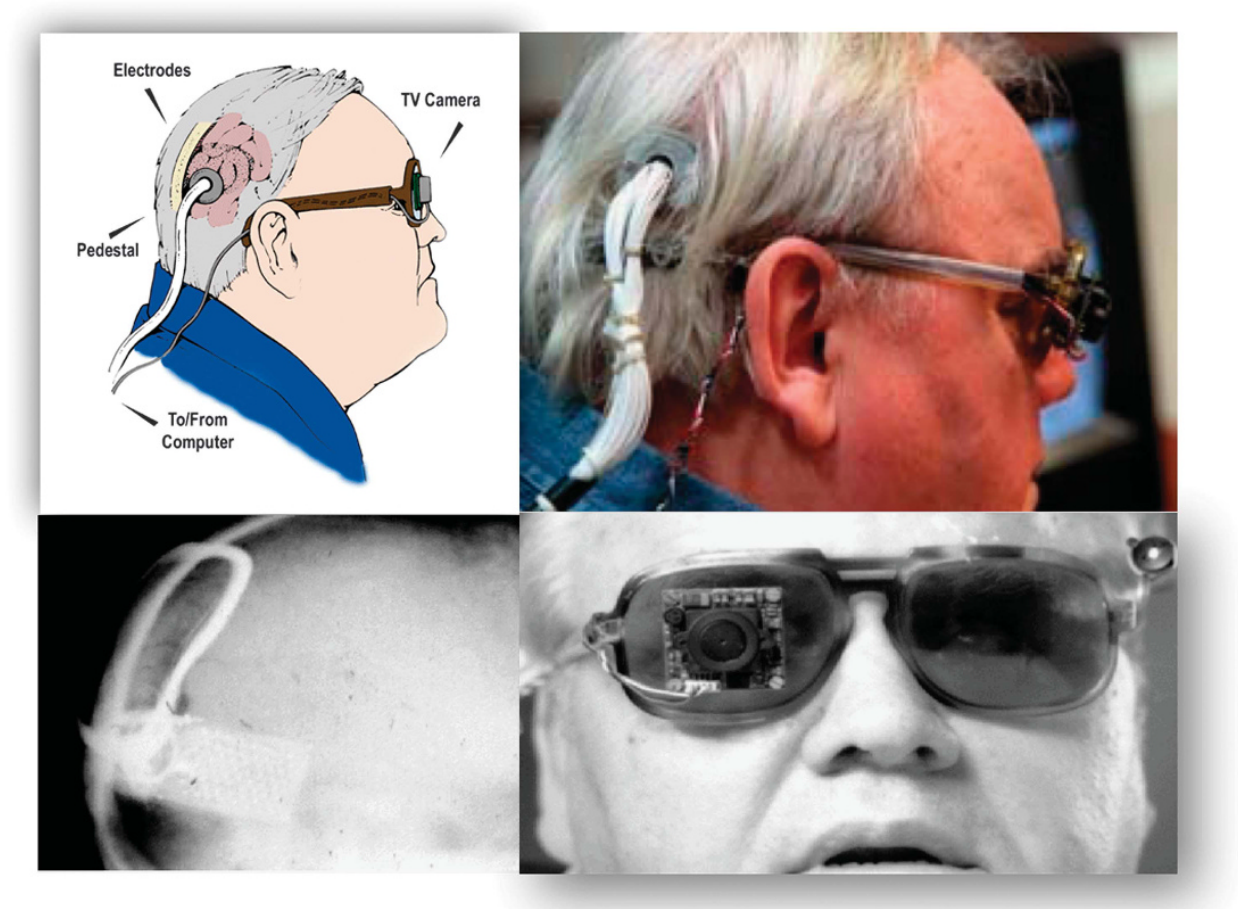

Figure 3 Different views of the stimulated of the visual cortex of hemianopic patients during neurovascular operations.

loss of vision. It focused researchers' efforts towards a retinal rather than cortical approach to artificial vision, despite commendable efforts to map the visual cortex for stimulation by Normann et $a l^{16}$ as shown in Figure 4.

An electronic retinal implant would need some functional retinal cells. Therefore, researchers would first have to prove that stimulation of the retina would be safe and generate phosphenes in a visual field. Previous cortical approaches had shown this was possible, but the number of functional retinal cells and types needed for a direct retinal approach was unclear. Over the next years, animal models became the mainstay of early research as 


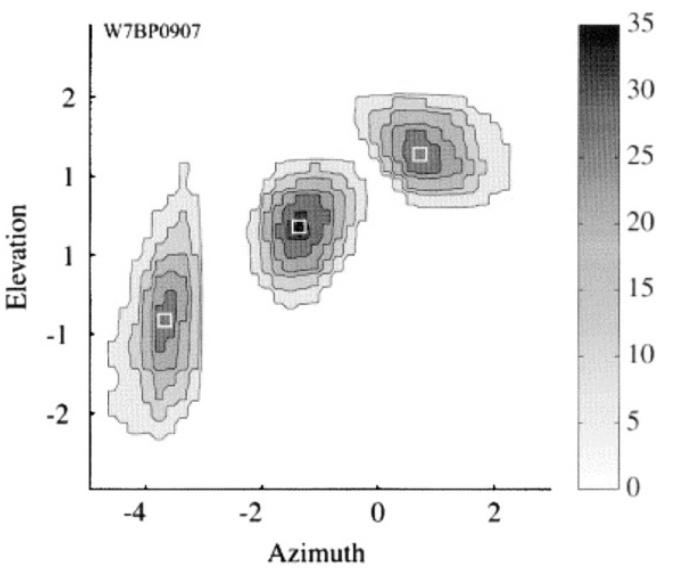

Figure 4 Method of mapping of the receptive fields of the visual cortex by Norman et al using an electrode array. The central square and darker shading indicating areas most likely to activate an action potential that would lead to a phosphene, based on recorded electrode stimulation.

the neural network in the retina of mice and rats is very similar to humans. ${ }^{17}$

\section{Epiretinal approach}

Early development of the epiretinal implants was pioneered by Humayun, Greenberg and De Juan et al from Southern California in the US, alongside the tremendous engineering efforts of Liu et al at North Carolina State University in the early 1990s. They would go on to develop the first Argus implant (Argus I, Second Sight LLC, Sylmar, CA, USA).

The team started in 1994 to not only assess phosphene generation, but most importantly to assess the safety of retinal stimulation - the electrical stimulation current to create phosphenes had to be within the then current safe limit of $100 \mu \mathrm{C} / \mathrm{cm}^{2}$. They used bullfrog retinae in an eyecup preparation and rabbit retinae with some being normal and the others with the outer retina scorched away by sodium iodate. A platinum wire electrode was applied to the retinae and a localised retinal response was observed. Additionally the surface charge densities were all within safe limits, and in the case of the rabbit retinae with outer cell loss, the charge densities were approximately a tenth of the allowed limit. ${ }^{18}$

Encouraged by the animal model, they pressed forward with a human trial. In 1996, they stimulated the retinae of five patients with small probes inserted through the sclera under local anaesthesia. Three patients had RP, one had AMD and another a retinal defect from birth, and hence were representative of the patient population such a device would be most useful for. The patients experienced phosphenes, with two of them able to track the phosphenes as the location of stimulation shifted. ${ }^{19}$
Over the next few years they undertook further research on more individuals and found similar results with additional information. The frequency of stimulation at which the cells were activated, and phosphenes appeared was found, which would be crucial for further device development. They also showed that the phosphenes could be manipulated in such a way as to allow the patient to see predetermined shapes. ${ }^{20}$

These findings suggested that theoretically an artificial vision device would work. Working with Humayun, Greenberg and De Juan et al, Liu et al in 1996 first proposed a dual unit prosthesis called an Artificial Retina Chipset (ARC), essentially consisting of a photosensing, processing and stimulating (PPS) chip implanted subcortically. This would subsequently be attached to a microelectrode array on the retina. The PPS design showed promise and was an engineering base for moving forward with the development of an implantable retinal prosthesis. $^{21}$

After this Liu et al further refined their implant design, and called it the Multiple-Unit Artificial Retina Chipset (MARC, North Carolina State University, Raleigh, NC, USA). They knew from the previous work of Humayun et al that the stimulating current should be $100-600 \mu \mathrm{A}$, pulse duration should be $0.1-0.2 \mathrm{~ms}$ at a frequency of 10-125 Hz, and that in RP and AMD almost all photoreceptors die but the inner ganglion and bipolar cells survive in good numbers. ${ }^{22,23}$ The device was therefore designed to replace photoreceptor function and consisted of an extraocular camera and microprocessor, connected wirelessly to an intraocular processing chip attached to an electrode array mounted on three possible materials of silicone rubber, thin silicon or polyimide. The final design called the MARC4 overcame previous issues such as heat dissipation, power supply, functionality, biocompatibility and retinal stress (only an electrode was mounted in the MARC4, not processors as well).

Despite advances in design, the long-term stability of the proposed implant was a pressing factor to evaluate. In early studies fixation and biocompatibility of the epiretinal electrode array to the eye had proven difficult, but it was not long before animal studies showed that implanting the electrode array was surgically feasible, there were no significant biocompatibility issues, and the implant had acceptable long-term results. ${ }^{9,24}$ Walter et al in 1999 implanted an electrically inactive epiretinal device into ten rabbits and followed them up for 6 months: the electrode array was secured with a tack to the retina. Nine of the 10 rabbits suffered no serious complications, with no long-term effects of surgery noted and no adverse instability in the implants or retinal detachment. ${ }^{9}$

The next stage of the journey focused on characterising the exact retinal cells that were being stimulated by devices, the numbers of functional retinal cells left in RP 
and AMD patients, and the effects of neuro-remodelling in blind patients that could potentially impede or facilitate the correct functioning of devices.

The retinal cells being activated by electrical stimulation were identified by Weiland et al in 1999. They decided that all retinal cell types through which electrode stimulation could be generating phosphenes should be investigated. Over the previous 3 years they had identified two patients who were undergoing eye removal for cancer. Under local anaesthesia krypton red and argon green lasers were used to obliterate certain cell types in different locations on the retina. Krypton red preserved photoreceptors, whereas argon green left only ganglion cells and axons intact. A handheld electrode was then used to stimulate the retinae. Normal retinae produced a dark perception and the laser treated retinae produced white perceptions, which led them to conclude that the focus for electrode devices should be the inner retinal layer. ${ }^{25}$

The question of what cells were being activated by electrode stimulation had been answered, but the numbers needed for a workable device had not. In 1999 Humayun et al published research that showed significant numbers of retinal cells survived in RP, by analysing human retinae from 18 patients diagnosed with $\mathrm{RP}$ and 11 age-matched controls. Although there was considerable inner, outer and ganglion cell loss, in the macula region the inner retina and ganglion cell destruction was not observed to the degree as previously theorised. ${ }^{26}$ After this they performed an additional study in AMD patients with comparable results. ${ }^{27}$ At the time, this gave momentum to the dream of an actual commercial device. The remaining concerns were: the number of remaining retinal cells needed for stimulated sight to be possible was still no clearer, and the consequences of potential neural network remodelling that had occurred in blind patients.

To answer the question of neural remodelling the underlying processes had to be understood. Research discovered it had 3 stages: stage 1: rod degeneration, stage 2: cone degeneration and stage 3: the global remodelling of the retinal nervous system. Through the clever use of immunoreactivity signals of GABA (gammaAminobutyric acid), glycine and glutamate, stage 3 neurites were shown to be capable of being created and new connections remodelled. ${ }^{28}$ Oligodendrocytes that should have been absent from mature retinas backed up this theory. ${ }^{29}$ It was therefore expected that even in blind patients, positive neural remodelling would occur.

Humayun $\mathrm{M}$ et al, who was part of the Doheny Eye Institute team, joined with Second Sight (CA, USA) to implant the first operational long-term epiretinal implants, the Argus I, into six patients between 2002 and 2004. The patients had vison loss secondary to retinitis pigmentosa to the level of bare or no light perception.
The implant was rudimentary by today's standards and consisted of an extraocular camera, wireless transmitter, extraocular receiver and a 16 electrode array. All patients were able to see discrete phosphenes in a reproducible fashion, detect some directional movement and simple shapes. The trial also concluded that smaller, more densely packed electrodes and rehabilitation of patients could improve results. 8,30

As a result, Second Sight (CA, USA) developed the upgraded Argus II implant a few years later. The Argus II has a 60-electrode array and an ongoing trial commenced in 2006 with estimated completion in 2019. In the trial 30 subjects were implanted with the implant and the results are discussed later.

At the same time another company, Intelligent Medical Implants (IMI), was developing a different epiretinal device. The IMI device development began in 1998 and was named the Learning Retinal Implant System (IMI Intelligent Medical Implants AG, Zug, Switzerland). It consisted of a digital camera and data transmitter confined in spectacles (termed the visual interface), a processor with software and power supply (termed pocket processor that could be worn on the wrist or elsewhere) and a receiver plus microelectrode array attached to the epiretina (termed the retinal stimulator). ${ }^{31}$ It was in reality a very similar device to the Argus I system.

The IMI device has been tested in humans. Initially it was implanted into four patients using a 49-electrode array with multiple stimulation tests over 12 months and was well tolerated, with the longest follow-up being 30 months and no gross changes seen on optical coherence tomography (OCT). ${ }^{32,33}$ More recently 20 subjects were implanted successfully with only one serious adverse event of retinal detachment, although follow-up was only 3 months. ${ }^{34}$

In 1995 the German Epi-Ret device was pioneered by Rolf Eckmiller at the University of Bonn, Germany, in cooperation with 14 other research groups. It is now known as the Epi-Ret 3 (Epi-Ret Project, Aachen, Germany). It was initially funded by 10 million Deutschmarks donated by the German government and was the intellectual property of Intelligent Implants that was founded in 1998 and termed the Learning Retinal Implant (RI). The device consisted of an external glasses frame with integrated photosensor array and an internal retinal stimulator implanted adjacent to the retinal ganglion cells that were wirelessly connected via induction with electromagnets. To compensate for possible spontaneous head and eye movements that blind individuals often experience, an encoder called the Learning Active Vison Implant Encoder (LAVIE) was also devised. ${ }^{35}$ In the first animal trials of the Epi-Ret device, difficulties arose with the attachment of the thin platinum 
microelectrodes to the retina. Despite being well tolerated, the microelectrodes spontaneously dislocated after a few days. $^{36}$

Events such as this caused great debate at the time between research groups as to the best method to manufacture and design of microelectrodes for the retina. Peterman et al investigated the feasibility of (a) substrate plates that direct neurites to attach; (b) neurotransmitter releasing chips; and (c) soft materials to use in chip manufacture. ${ }^{37}$ Previously, retinal microelectrode arrays were designed to stimulate entire fields of retinal neurons and had been implanted at a distance of $50 \mu \mathrm{m}$ away from them. Although this distance is not large, the overall length has been proven to have profound effects on device resolution and power requirements. A microelectrode array that could stimulate single neurons would have to have a density of electrodes greater than that of retinal neurons. It was a tough order, and was stopped at the time by the limits in retinal cell regeneration biochemical knowledge as the use of growth factors to direct neurites would have been needed.

Arguably the greatest advancement made by the research team was the development of materials for the electrode array template. Prior arrays had been made of hard inflexible silicone at great cost but there had been promising results for a flexible array approach. ${ }^{38,39}$ Peterman et al showed that a cheaper flexible array could be made that would fit the shape of the retina, with the added advantages of greatly reducing surgical skill needed and achieving a better contact with retinal neurons.

\section{Subretinal approach}

Subretinal device design first started in the late 1980s by a company called Optobionics Corp (Illinois, USA) that was founded by Alan and Vincent Chow. They were the first to receive a patent (U.S. Patent No. 390 562) for an artificial subretinal device in 1991, called the Artificial Silicone Retina (ASR, Optobionics Corporation, Naperville, IL, USA). ${ }^{40}$

Initially, animal models showed the long-term capabilities of such a device. In one study cats were used (due to similarities of ocular blood circulation to the human eye) as implant subjects and two different types of implant were used: a single photodiode and a microphotodiode array consisting of many individual photodiodes arranged in square formations. The cats were followed up over 10 to 27 months. The implants stayed in position with good biocompatibility, however the gold used in the electrodes dissolved over time and the efficiency of the implant decreased over time as a result. ${ }^{41}$ Clearly, the materials used had to be carefully considered before future human use.
A few years later Optobionics implanted six patients with RP. The implant design had been modified and silicone was used as the main material. All of the patients reported a subjective improvement in vision, but in an unexpected pattern. One would expect only the retinal area directly in contact with the stimulating electrodes to produce phospenes. In contrast, Chow et al found that significant proportions of the retina not stimulated by the electrodes showed some improvement in vision. A wide variety of peripheral vision changes in the Humphrey visual fields post-operatively were observed. ${ }^{42}$ This led many to believe that the visual improvements were due to neurotrophic effects rather than the implant itself. Further research showed that implanting a device did indeed cause the release of protective neurotrophic factors, and higher stimulating current levels were even more protective. ${ }^{43,44}$

In addition, because the ASR device used photodiodes, they would only produce small currents upon light stimulation. Research soon showed that $10^{-6} \mathrm{~A}$ was needed for patients to elicit visual perceptions. A maximum predicted current of $10^{-9} \mathrm{~A}$ could be produced by photodiodes, which is insufficient to generate a visual percept. $^{45}$

At the same time, a company called Retina Implant $\mathrm{GmbH}$ in Germany was also developing a device called the Retina Implant (RI), led by E. Zrenner. This would later be known as the Alpha-IMS device (Retina Implant AGy). The company built on the many years of research on artificial vision by German universities and physicians. The device was similar in many respects to the Optobionics ASR but with one crucial difference; as the current produced from photodiodes is insufficient to properly elicit phosphenes, the RI device had an amplifier for each microphotodiode to increase the current and therefore the stimulation power. The device had 16 wireconnected electrodes, which produced a $38 \times 40$-pixel visual pattern. The power supply or battery was external, and was supplied to the chip via a subdermal cable that passed under the temporal muscle. ${ }^{46}$

Zrenner et al implanted 11 patients with the RI (there were 12 but one subject withdrew his/her consent), seven with RP, three with cone-rod dystrophy and one with choroideremia. To discover which subjects could perceive light they used direct stimulation electrodes to discover phosphene patterns. Six out of 11 could discern phosphenes with single electrode stimulation and eight with multiple electrodes stimulation. The study was complicated by different research periods for different patients, as well as first- and second-generation devices being implanted. The first generation had smaller electrodes of $50 \mu \mathrm{m} \times 50 \mu \mathrm{m}$, versus $100 \mu \mathrm{m} \times 100 \mu \mathrm{m}$ in the second; larger electrodes produced better visual percepts. Eight subjects were implanted with the 1st generation 
device and studied for 4 weeks, and three subjects were implanted with a second-generation device and studied for 4 months. Of the 6 patients tested, 5 could distinguish basic patterns such as lines to a significant level, but none of the three patients with the second-generation device could distinguish complex patterns such as letters to a significant level. This was a disappointing result for the team, and they thought it was due to poor spatial resolution caused by (a) different electrode threshold voltages and (b) current dissipation in the retina causing interference or crosstalk to unwanted ganglion cells. There was some good news, however, with one of the three subjects that received the improved secondgeneration device being able to visualise shapes and navigate in a room towards a person, with the other two of three being able to distinguish bright objects against a dark background. ${ }^{46,47}$

With some promising results, it was not long before the team then commercialised the device for medical use and called it the Alpha-IMS. It has a completely wireless power system using inductive energy transfer. A primary coil in the post-auricular transmitter part of a handheld device that could control the contrast and gain, would charge and hence create current in a secondary coil in the ocular implant part by induction. The Alpha-IMS also has a microphotodiode array with 1500 electrodes. ${ }^{48}$

\section{Today's devices}

There are currently five main retinal devices that are approved or still in pre-commercial development stages, detailed in Table 1. Previous reviews have shown that the Argus II Retinal Prosthesis System and the Alpha-IMSg Retina Implant AG are the most likely to succeed in being the first devices to be widely used clinically. ${ }^{49,50}$

The purpose of the next section is to review these two devices and to compare them in terms of (a) safety profile, (b) improvement in visual function and (c) surgical technique.

However, it must be noted that for both technologies, we have based our comparisons on data published in the peer-reviewed literature. For the Argus II we have used the 3 plus the 5-year trial results and for the Alpha-IMS the 1 year trial results in this comparison. This is due to the final results of the 10 year Argus II trial not being available until 2019 estimated, and similarly with the final results of the Alpha-IMS trial will not be available until 2018 estimated.

\section{Argus II retinal prosthesis system}

The Argus II Retinal Prosthesis System received European approval (CE mark) in 2011 and United States approval (FDA approval) in 2013. ${ }^{50}$ The prosthesis consists of an

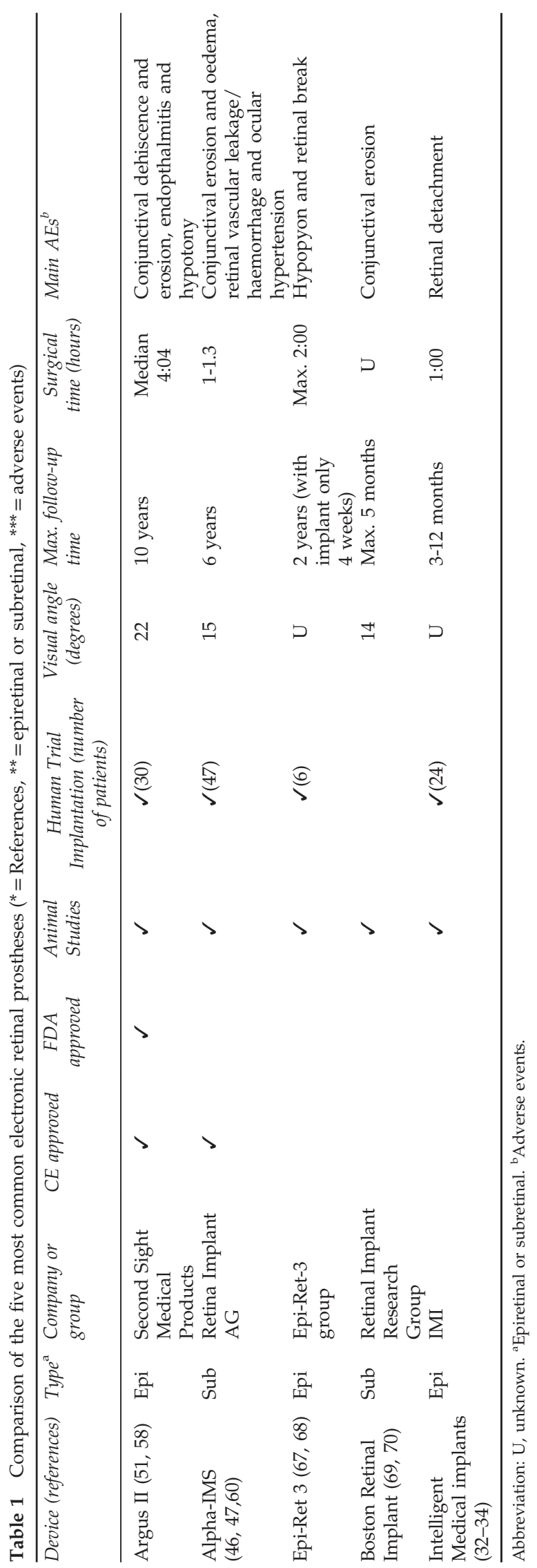


external unit of a pair of glasses with mounted camera and transmitter coil, connected to an image processer and battery worn in a belt or shoulder strap as shown in Figure 5 .

The internal portion consists of a receiver/transmitter coil, electronics case and a 60-electrode array that is surgically implanted epiretinally using a tack. The electronics case and the array are connected via a polymer wire, with the external and internal units connected wirelessly using induction. A video is captured by the camera and using battery power, this creates a current that then causes flux in the external transmitter coil that by induction creates a current in the internal coil. ${ }^{51}$ Figure 6 illustrates the external appearance of the system. Since then the device has been implanted in over 200 patients to date.

The Argus II has been shown to increase patients' (blinded by outer retinal dystrophies) ability to recognise characters or short words, to perform visual activities of daily living, and to succeed in both orientation and mobility tasks. ${ }^{52-55}$ Five year results of visual performance and quality of life experienced by the patients from the Argus II trial have been reported in early 2016 at the 39th Annual Macula Society Meeting and recently published in the journal Ophthalmology. The results are discussed throughout the next sections. ${ }^{56,57}$

\section{Safety profile}

The international multicentre phase II clinical trial of the Argus II device began in 2007. In this trial, the device was implanted into 30 patients, mainly RP patients, with bare or no light perception with visual acuity less than $2.9 \mathrm{log}$ MAR in both eyes. The main outcome of the trial was serious adverse events (SAE), with the secondary outcome of assessing visual improvement. Interim results of this 10-year trial were published in 2012, 2015, and 2016. In the first report, the patients had been followed up for a minimum of 6 months to a maximum of 2.7 years at this time. 21 out of 30 or $70 \%$ of the patients did not experience a SAE, but in those who did there were 17 SAEs. The three most common SAEs were conjunctival dehiscence, endophthalmitis, and hypotony, and over $80 \%$ of the SAEs occurred within 6 months of post implant. ${ }^{51}$

In 2015 the 3 year follow-up results of the Argus II clinical trial were published. Eleven of 30 patients experienced SAEs, and in total there were 23 device or surgery related SAEs with the most common still being conjunctival dehiscence, conjunctival erosion, endophthalmitis and hypotony. Figure 7 shows the comparison of the short and long-term SAEs. The device itself was followed up for a total of $\sim 90$ patient years, 29 of the 30 implanted Argus II devices still worked at 3

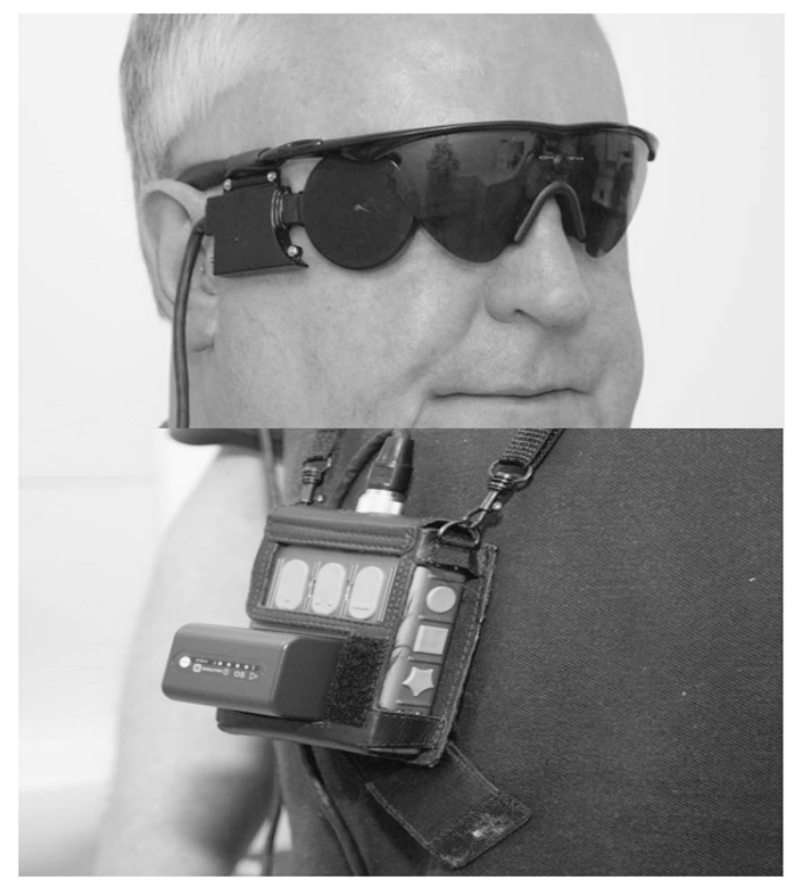

Figure 5 Argus II prosthesis external components. Top image shows the external glasses. The prosthesis consists of an external unit of a pair of glasses mounted with a camera and micro processing unit.

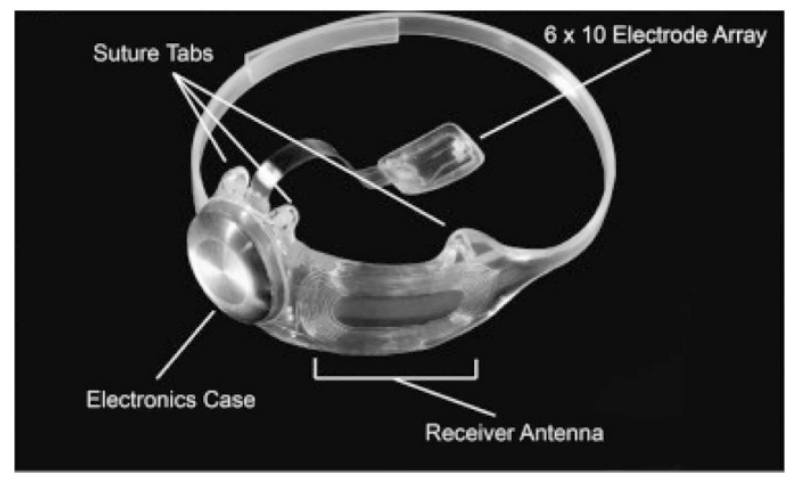

Figure 6 Argus II internal design, showing the array of electrodes and the electronics casing. From da Cruz L et al. ${ }^{57}$

years and this showed the device was both biocompatible and reliable. The authors admit small sample size and low statistical power does limit the overall application of this safety profile for full commercial use. ${ }^{58}$ At 5 years postimplant only $1 \mathrm{SAE}$ in addition to the 3 year results was reported; a rhegmatogenous retinal detachment. ${ }^{56,57}$

\section{Visual improvement}

All patients in the trial were evaluated using complete eye exams, retinal fundus photography, fluorescein angiography, optical coherence tomography (OCT) at day 1 , weeks 1, 2, and 4, and at months 3, 6, 9, 12, 18, 24, 30, 


\begin{tabular}{|c|c|c|c|c|c|c|}
\hline \multirow[b]{2}{*}{ SAE Type } & \multicolumn{3}{|c|}{ Year 1} & \multicolumn{3}{|c|}{ Year 3} \\
\hline & $\begin{array}{l}\text { No. of Subjects } \\
\text { with SAE }\end{array}$ & $\begin{array}{l}\text { \% of Subjects } \\
\text { with SAE }\end{array}$ & $95 \% \mathrm{CI}$ & $\begin{array}{c}\text { No. of Subjects } \\
\text { with SAE }\end{array}$ & $\begin{array}{l}\text { \% of Subjects } \\
\text { with SAE }\end{array}$ & $95 \% \mathrm{Cl}$ \\
\hline Conjunctival erosion & 3 & $10.0 \%$ & $2.1-26.5$ & 4 & $13.3 \%$ & $3.1-30.7$ \\
\hline Hypotony & 2 & $6.7 \%$ & $0.8-22.1$ & 4 & $13.3 \%$ & $3.1-30.7$ \\
\hline Conjunctival dehiscence & 3 & $10.0 \%$ & $2.1-26.5$ & 3 & $10.0 \%$ & $2.1-26.5$ \\
\hline Presumed endophthalmitis & 3 & $10.0 \%$ & $2.1-26.5$ & 3 & $10.0 \%$ & $2.1-26.5$ \\
\hline \multicolumn{7}{|c|}{$\mathrm{Cl}=$ confidence interval; $\mathrm{SAE}=$ serious adverse event. } \\
\hline
\end{tabular}

Figure 7 Comparison table reproduced from the long-term results of the Argus II trial showing the 1 year (short term) and 3 year (long term) occurrence of SAE. From Ho A et al. ${ }^{58}$
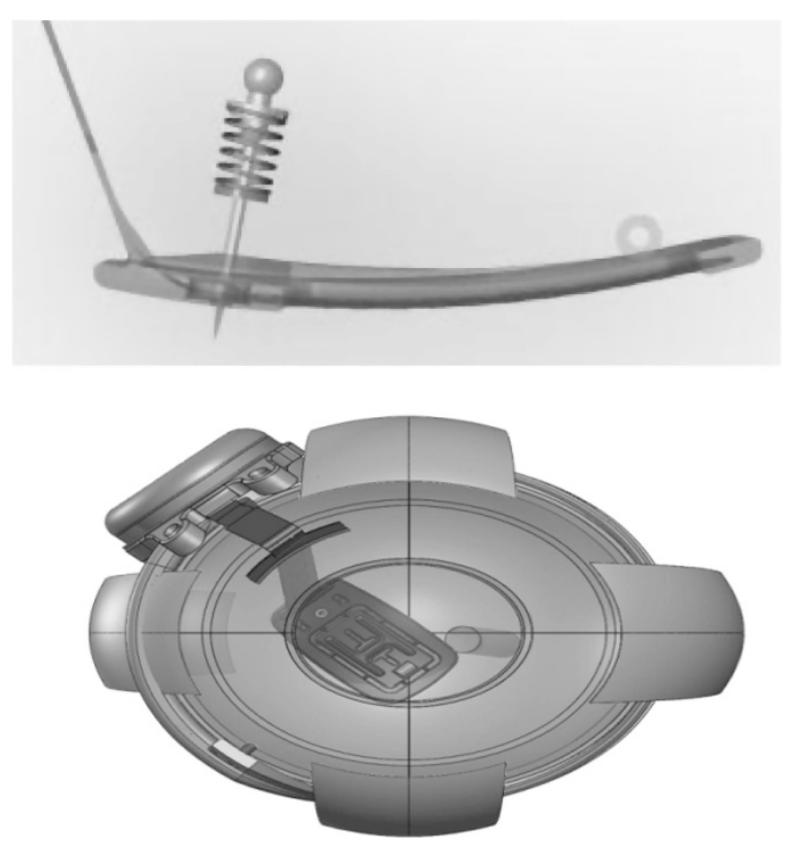

Figure 8 Top of Figure: Design of the bespoke surgical tack. Bottom of Figure: array tacked over the macula and the electronics case at the side of the eye.

and 36. The visual function of the patients was tested using several tests including Square Localisation (locate and touch a white square on a black monitor displayed at randomly generated locations on the screen), Direction of Motion (patients had to correctly identify the direction of movement of a white bar that moved across the screen) and Grating Visual Acuity (measured logMAR from 2.9 to 1.6 using black and white gratings displayed for 5 seconds).

Better visual performance was recorded in all three tasks in $89 \%, 56 \%$ and $33 \%$ of patients, respectively, with Argus II system turned on, at 3 years post implantation. Independent assessment by a rehabilitation specialist of the impact of the device on quality of life (using the Functional Low-vision Observer Rated Assessment (or FLORA, based on both assessors and patients opinions' of benefit) stated that $80 \%$ of the patients had received benefit in their functional vision and/or well-being at 1 -year post implantation. FLORA involved an in depth interview and observation of patients in a real-world environment at home. For those subjects who had a measurable visual acuity with the Argus II, the Grating Visual Acuity logMAR measurements had a mean of 2.5 at 1 year and 2.5 at 3 years, suggesting that the visual improvement is sustained over a medium-term. ${ }^{58}$ Furthermore, 5-year results report that increase in visual function is maintained long-term despite two devices failing at 4 years post implantation. ${ }^{56}$

\section{Surgical technique}

The full surgical technique for Argus II implantation can be obtained from the appendix of the long-term trial results of the multicentre phase II trial. ${ }^{58}$ The following is a summary of the surgical technique.

Only aphakic eyes were implanted. After a $360^{\circ} \mathrm{limbal}$ conjunctival peritomy and isolation of the rectus muscles, the coil is inserted under the lateral rectus muscle and the electronic package centred on the superotemporal quadrant. The implant is fixed to the eye by both direct suturing to the globe and by means of a $360^{\circ}$ scleral band that is part of the Argus II explant and using mattress sutures or scleral tunnelling.

Following complete vitrectomy with induction of detachment of the posterior hyaloid, the array is inserted through an enlarged temporal sclerotomy and placed and tacked over the macula using a custom retinal tack shown in Figure 8. All sclerotomies are then closed. The external component of the device; the cable entry and anterior part of the receiver, are covered with a donor sclera allograft (or suitable alternative). Intravitreal and subconjunctival antibiotics are finally administered.

The surgery time ranged from 1.53-8.32 hours with a median of 4.04 . The authors stated that the longest surgical time was due to the patient having had multiple previous surgeries resulting in extensive conjunctival scarring, suggesting avoidance of such patients. 


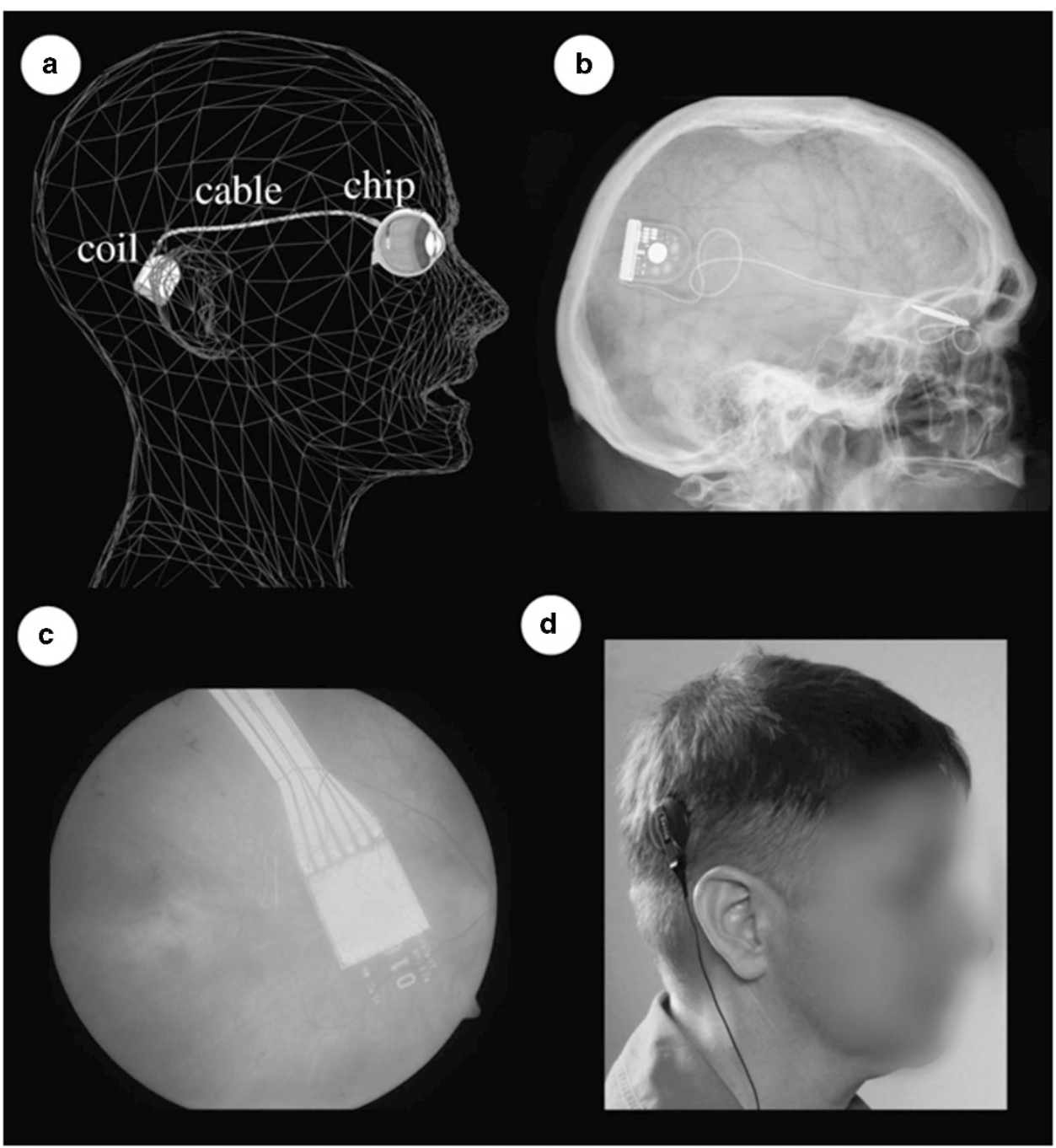

Figure 9 Alpha-IMS implant: different viewing modalities of the array of electrodes attached to a power cable that loops in the orbit before becoming extraocular and travelling subdermally towards a post-auricular coil. From Stingl K et al. ${ }^{48}$

\section{Alpha-IMS}

The Alpha-IMS by Retina Implant AG has 1500 pixels on its chip, and each pixel has a photodiode that converts light into electrical impulses, amplifies the current and transmits it to surviving retinal cells via electrodes. The chip is $9 \mathrm{~mm}^{2}$ in area and $70 \mu \mathrm{m}$ thick after being encased in polyimide. The electrode array is attached to a power cable that loops in the orbit before becoming extraocular and passing subdermally to a subdermal post-auricular coil, as shown in Figure 9.59

Current or power supply is induced in the postauricular coil by a charged external coil that is attached to an external battery pack and control unit. The power of the amplifiers can be adjusted using the controls to produce the required brightness or contrast, and is a subjective process. ${ }^{48}$ There have been two trials of the Alpha-IMS device in humans.

One of the studies is a multicentre international trial and is still ongoing. ${ }^{60}$ This will be discussed in this section, with the prior study discussed earlier. The trial had 29 patients who received the implant in one eye only. Twenty of the patients had light perception without projection and 9 had no light perception. RP was the primary diagnosis in 25 , and the remaining 4 patients had cone-rod dystrophy. The primary outcome was improvement in activities of daily living (ADL) assessed using visual tests, and secondary outcome was increased light perception or object recognition. The follow-up period was 1 year from implantation. ${ }^{60}$ The trial is currently ongoing and at the time of writing only these 1 -year results are available in peer-reviewed literature.

\section{Safety profile}

The fundamental safety and biocompatibility of the Alpha-IMS device has been assessed in previous years using animal models. The results reported here are from 


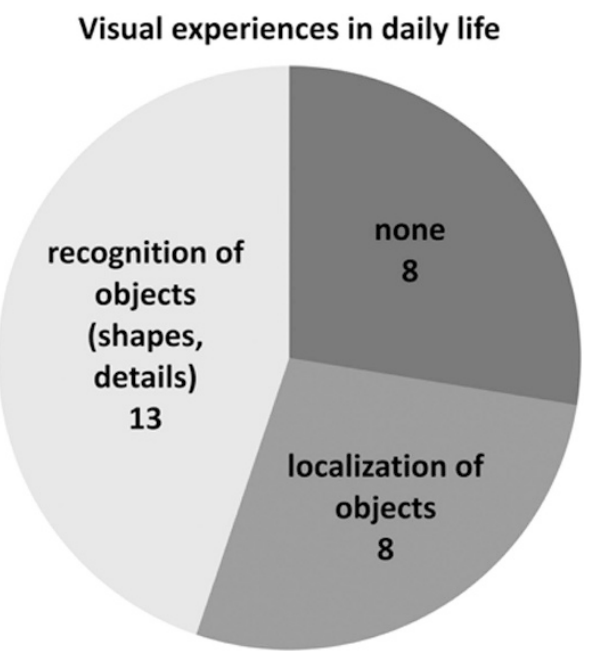

Figure 10 Alpha-IMS trial self-reported increase in daily living activities such as locating objects and shapes in grey scale. Examples of objects identified were people/faces, buildings and vehicles. From Stingl K et al. ${ }^{60}$

the first nine patients implanted with the device at 1-year post implant and at one centre. ${ }^{61}$ The comprehensive safety data will be reported at a later date. ${ }^{60}$ In the nine patients two SAEs occurred: raised intraocular pressure (IOP) of $46 \mathrm{~mm} \mathrm{Hg} 5$ days after implantation and retinal detachment 1-day post device removal. Despite this encouraging SAE rate, the first part of the trial performed at one centre suggests possible safety concerns. A total of 75 adverse events overall occurred in the nine implanted patients. Fifty-three of them affected the eye and its adnexa, with 31 resulting from the implant. Eleven of the 53 ocular events remained unresolved a year later. The authors state that the majority of the most difficult adverse event cases were due to surgical positioning or removal of the device. ${ }^{61}$

\section{Visual improvement}

The Alpha-IMS implant was turned on and off for various tests to assess possible improvement in daily living. The tests consisted of geometric shape localisation and identification, table top object localisation and identification, clock hand identification at 0,90 , and $180^{\circ}$ to each other, reading white letters on a black background, grey shade identification and patient reports of improvement in quality of life.

Overall $72 \%$ of the patients reached a statistically significant improvement in ADLs, and 86\% had an improvement in light perception or visual acuity (the secondary outcome). Despite this, only $45 \%$ or 13 patients self-reported an increase in daily life experiences, shown in Figure 10, relating to the ability to see objects or shapes in grey scale; examples of objects identified were people/faces, buildings and vehicles. It is also important to note that the authors found an increase in visual function in some patients over time with the implant turned off; they hypothesised this may be due to release of growth factors, a phenomenon known to happen with artificial vison device implantation. ${ }^{62}$ In addition, over the entire course of the study, patient visual improvement declined with the device turned on. This was due to device failure and led to a change in surgical implantation technique. $^{60}$

\section{Surgical technique}

The full surgical technique for Alpha-IMS implantation has been summarised here. ${ }^{59}$ The surgical procedure involves an extraocular and an intraocular component. This procedure is undertaken under general anaesthesia. Accurate marking of skin incisions and implant position behind the ear and at the orbital rim is facilitated by the use of a nonsterile model of the whole implant.

The extraocular technique involves fashioning a subperiosteal tunnel from the infraorbital region, extending beneath the temporalis region to the retroauricular area. A cable is directed along this tunnel from the subretinal implant to a coil positioned externally behind the ear.

The intraocular procedure involves performing a $360^{\circ}$ peritomy of the conjunctiva at the limbus. A tunnel is prepared through the orbital septum from the conjunctival space in the upper temporal quadrant to the skin incision at the orbital rim. The implant is pulled through the tunnel to the subconjunctival space and placed to one side whilst the intraocular procedure takes place.

The electrical integrity and functionality of the implant was ascertained in all cases at the end of the pull through procedure.

Extraocular surgery took about $60-80 \mathrm{~min}$. Two different surgical teams performed the extraocular and intraocular procedures. The intraocular procedure involved the fashioning of an upper temporal quadrant scleral flap, completing a full vitrectomy, elevating the retina surgically and then inserting the implant through the choroid, into the subretinal space and positioning subfoveal. The implant and scleral flap are then sutured. The retina is flattened and intraocular silicone oil used as a tamponade.

\section{Argus II vs Alpha-IMS design}

Two very different approaches have been taken in the design of these two devices. The Argus II uses an external camera with an image processor to convert an image into electrical impulses for ganglion cell stimulation, whereas 
the Alpha-IMS directly senses intraocular light and converts it to electrical energy using an amplifier and contrast unit to control the intensity of the stimulation.

The Argus II has 60 electrodes and covers $11^{\circ} \times 19^{\circ}$ in the visual field ( $\sim 22^{\circ}$ diagonally). This contrasts with the Alpha-IMS that has 1500 electrodes and covers a smaller visual field of $10^{\circ} \times 10^{\circ}\left(15^{\circ}\right.$ diagonally). A larger electrode number gives a higher resolution advantage, which can be defined as the ability to distinguish smaller objects / detail. The Alpha-IMS has a theoretical resolution of $0.5^{\circ}$, 8 times greater the theoretical maximum resolution of $4^{\circ}$ of the Argus II. Despite this, the real-world difference in visual acuity performance reported between the two devices has been found to be marginal. The next generation Argus device will be a higher-acuity retinal implant, with 240 electrodes and a cortical 60-electrode implant suggested. Despite differences in design, a fundamental factor to achieve good visual improvement with both devices is the quality of electrode-tissue interface. Improved designs or surgical procedure will likely aid this in the future. ${ }^{63}$

In terms of real-world ease of use for a patient, the advantage of the Alpha-IMS device is that normal eye movements can be used, whereas in the Argus II device head movements are needed to refresh the image and large eye movements should be avoided. That said, previous experiences have shown that Argus II patients adopt scanning head movements well with training. The advantage of the Argus II device is that individual electrodes can be adjusted for gain and offset, whereas in the Alpha-IMS device these parameters can be adjusted for all the electrodes but not individually. Another consideration in detecting movement is device refreshment rate. Different individuals require different frequencies of image refreshment to achieve their optimal vision, with Alpha-IMS set at $1-20 \mathrm{~Hz}$ and the Argus II set at $3-60 \mathrm{~Hz}$. Theoretically the faster the refreshment rate the better the visual performance, but individuals find that they can experience fade with it set too high. For example, the Alpha-IMS has a stated maximum recognisable speed of $35^{\circ}$ per s, or approximately equivalent to a car moving at $14 \mathrm{mph}$ at a distance of $10 \mathrm{~m} \cdot{ }^{48,63}$

\section{Safety comparison}

Both research groups defined a SAE according to ISO EN 14155 (medical occurrences that either: caused death; were life threatening; caused permanent impairment of a body function or permanent damage to body structure, or necessitated medical or surgical intervention to preclude such impairment or damage; required hospitalisation or prolonged hospitalisation; or caused foetal death or abnormality). The direct comparison of SAEs is made difficult due to the differing interpretations of the ISO EN 14155 by each research group, difference in follow-up time (5 years for Argus II vs 1 year for Alpha-IMS trial) and the non-availability of the long-term results of AlphaIMS trial.

The Argus II trial recorded 24 AE, compared to only 2 SAE in the Alpha-IMS patient trial. Despite the difference in patient numbers this is a large discrepancy. When the results are analysed further, it can be observed that the Argus II trial allocated medical problems to SAEs while the Alpha-IMS trial did not. A good example of this is conjunctival erosion that the Argus II group classified as a SAE, whereas the Alpha-IMS group classified it as a nonserious event. However, if you follow a strict definition of seriousness defined in the ISO 14155 a conjunctival erosion, which requires a medical intervention to avoid a risk of infection which could develop in endophthalmitis would unequivocally qualify as a serious adverse event. It is therefore prudent to add together the SAEs and adverse events that the Alpha-IMS group classified as certainly caused by the device or surgery. The total SAE for the Alpha-IMS therefore turns out to be 34. Eleven ocular adverse events were marked as unresolved after 1 year, of which 9 were retinal vascular leakage and neovascularization, as shown on fluorescein angiography, and 2 were retinal breaks without detachment. At the end of the year-1 evaluation, none of these 11 required intervention, although with longer-term results this may change. ${ }^{58,61}$ This is the only information we have been able to find in the published literature.

The five year follow-up results for the Argus II device are now available, and importantly only 1 further SAE has been observed. Encouragingly, of the 111 commercial implants (implants outside trials) the percentage rate of SAEs that are conjunctival dehiscence and erosion, endopthalmitis, retack and retinal detachment are significantly less than in the Argus II trial results (as of July 2015). ${ }^{56}$ No long-term SAE assessment for the AlphaIMS has been reported.

\section{Visual improvement comparison}

Both research groups found significant increases in visual acuity and task performance. The direct comparison of visual improvement is difficult due to different tests being used by each research group to calculate visual improvement, as detailed above.

A meaningful comparison can be made on the improvement in quality of life of implanted patients. For the Argus II quality of life was independently assessed using the specifically developed FLORA (see 'Safety profile' for further details). The independent assessment team recorded that $80 \%$ of patients had benefited in their functional vision and/or quality of life at 1-year post 
implantation, and none experienced negative effects. ${ }^{58}$ This positive effect has recently been shown to be maintained at 3 years post implantation. ${ }^{56}$ This is comparable to a statistically significant improvement in ADL recorded by the research group in $72 \%$ of patients implanted with the Alpha-IMS, however, 8 of 29 patients did not experience benefit from the implant in daily life. ${ }^{60}$ Long-term quality of life results for the Alpha-IMS will not be available until 2018 .

\section{Economic analysis}

No economic model exists for the Alpha-IMS device.

The economic case for the Argus II prosthesis was analysed by Vaidya et al ${ }^{64}$ in 2014 . They used a theoretical cohort of $1000 \mathrm{RP}$ patients that were aged 46 and followed up over 25 years and applied a Markov model. The economic analysis took into account the usual healthcare costs of RP patients, such as nursing care and rehabilitation, that was calculated as $€ 12000$ per annum. Health outcomes were expressed in quality adjusted life years (QALYs) and the costs were in the 2012 value of the euro.

Second Sight provided the costs from patient eligibility to annual upgrade of the device. If QALYs were considered, the incremental cost effectiveness ratio or ICER was $€ 14,603 /$ QALY assuming a 25 year device lifespan, which is inside the current NICE cutoff of $£ 10000-£ 20000$ limit. $^{65}$ The cost of a SAE was estimated at $€ 1000$ per event, with a cost of $€ 2000$ per explantation. An obvious variable that was considered in the economic analysis is the theoretical and actual lifespan of the Argus II. If the devices only last 10 years, the lifespan of which is not yet determined in real-world implantation, the ICER increases to $€ 50000 /$ QALY assuming over time cost reductions. ${ }^{64}$ Despite this, the Argus II device is forecast to be a cost-effective device and within the ICER limit for most European countries.

If one considers the economic effect of blindness to the overall economy, the picture becomes clearer. It is estimated that RP alone costs $€ 6$ billion when taking into account loss of working days, taxes and cost to a healthcare system. ${ }^{64}$ In addition, worldwide there are 285 million visually impaired individuals and many could be suitable for an implant. ${ }^{1}$

The above figures make it evident that if an artificial vision device could return enough visual acuity for patients to function in a working environment competently, then the economics favour their use, especially if production or device sale cost (currently around $\$ 100000$ for Argus II $)^{66}$ and number of SAEs decreases as the number of implanted patients increases.

\section{Conclusion}

The trials of both Argus II and Alpha-IMS devices have shown that an artificial vision retinal implant is now a feasible therapy for patients blind because of RP and both devices have an acceptable safety margin.

The ability for blind patients to experience again visual function is remarkable, and every effort from different research groups around the world should be highly commended. Despite this feat, the usefulness of the technology is limited by our current knowledge of neural visual processes and ability to manufacture artificial photoreceptors that resemble the complexity of the original. Research has shown that both the Argus II and Alpha-IMS restore some visual function and increase the quality of life to some patients, but increases in resolution and visual field in the future may improve daily life benefit even more.

We have tried through this review exercise to represent as fairly as possible the state of the most likely to succeed artificial vision devices. Ultimately, the future of such devices will be decided by an economic argument for which there is a strong case as previously discussed. For this to occur, however, the number of eligible patients and indications in blinding conditions needs to increase, as RP is a rare condition. This has been realised and as a result of this, a trial into the use of the Argus II device in AMD patients is currently underway at the Manchester Royal Eye Hospital, UK. If successful in this group of patients as well as in RP, then the economic case for retinal implants becomes a convincing one. Indeed, Forbes magazine has identified that the application of the Argus II device into AMD patients led by Professor Paulo Stanga at Manchester Royal Eye Hospital has quintupled the market for this device.

Furthermore, a positive recommendation from advisors to the UK Government's healthcare funding authority for specialised services in England, has led to the first publicly funded trial of the Argus II device in selective group of severely blind patients with Retinitis Pigmentosa by NHS England. The agreement is to fund the treatment via the Commissioning through Evaluation scheme, in which NHS England will conduct a 12-month clinical trial to evaluate the real-life benefits to patients of using the device. From this evidence, NHS England will make a decision whether to routinely fund the treatment in eligible patients. This a promising step towards the widespread commercial use of not just the Argus II device, but all retinal prostheses in the near future.

\section{Conflict of interest}

The authors declare no conflict of interest. 


\section{Acknowledgements}

PES: Second Sight Medical Products Inc. (Consultancy, Equipment, Research Funding, Lecture Fees, Travel expenses).

\section{Disclaimer}

In this review article, the authors have tried to the best of their ability to portray the current evidence in a non-biased and objective way. The views, opinions or conclusions are purely those of the authors and are not those of any other organisation or body.

\section{References}

1 World Health Organisation. Visual Impariement and Blindness. WHO, 2014 Fact Sheet 282 (29 June 2016).

2 Pascolini D, Mariotti SP. Global estimates of visual impairment: 2010. Br J Ophthalmol 2012; 96(5): 614-618.

3 Testa F, Maguire AM, Rossi S, Pierce EA, Melillo P, Marshall $\mathrm{K}$ et al. Three-year follow-up after unilateral subretinal delivery of adeno-associated virus in patients with leber congenital amaurosis type 2. Ophthalmology 2013; 120(6): 1283-1291.

4 Artificial vision: Medical Dictionary; 2009. Available from http:/ / medical-dictionary.thefreedictionary.com/artificial +vision (accessed on 29 June 2016).

5 Franklin B, Watson W. An account of Mr. Benjamin Franklin's treatise, lately published, intituled, experiments and observations on electricity, made at Philadelphia in America; By Wm. Watson, F. R. S. Philos Trans 1751; 47: 202-211.

6 LeRoy C. Où l'on rend compte de quelques tentatives que l'on a faites pour guérir plusieurs maladies par l'électricité. Hist Acad Roy Sciences (Paris), Mémoire Math Phys 1755; 60: 87-95.

7 Sachs HG, Gabel V-P. Retinal replacement-the development of microelectronic retinal prosthesesexperience with subretinal implants and new aspects. Graefes Arch Clin Exp Ophthalmol 2004; 242(8): 717-723.

8 Humayun MS, Weiland JD, Fujii GY, Greenberg R, Williamson R, Little J et al. Visual perception in a blind subject with a chronic microelectronic retinal prosthesis. Vision Res. 2003; 43(24): 2573-2581.

9 Walter P, Szurman P, Vobig M, Berk H, Ludtke-Handjery $\mathrm{HC}$, Richter $\mathrm{H}$ et al. Successful long-term implantation of electrically inactive epiretinal microelectrode arrays in rabbits. Retina 1999; 19(6): 546-552.

10 Hodgkin AL, Huxley AF. A quantitative description of membrane current and its application to conduction and excitation in nerve. J Physiol 1952; 117(4): 500-544.

11 Brindley GS, Lewin WS. The sensations produced by electrical stimulation of the visual cortex. J Physiol 1968; 196 (2): 479-493.

12 Dobelle WH. Artificial vision for the blind: The summit may be closer than you think. ASAIO J 1994; 40(4): 919-922.

13 Dobelle WH, Mladejovsky MG. Phosphenes produced by electrical stimulation of human occipital cortex, and their application to the development of a prosthesis for the blind. J Physiol 1974; 243 (2):553-576.
14 Dobelle WH, Mladejovsky MG, Evans JR, Roberts TS, Girvin JP. /'Braille/' reading by a blind volunteer by visual cortex stimulation. Nature 1976; 259(5539): 111-112.

15 Portera-Cailliau C, Sung CH, Nathans J, Adler R. Apoptotic photoreceptor cell death in mouse models of retinitis pigmentosa. Proc Natl Acad Sci USA 1994; 91(3): 974-978.

16 Normann RA, Warren DJ, Ammermuller J, Fernandez E, Guillory S. High-resolution spatio-temporal mapping of visual pathways using multi-electrode arrays. Vision Res 2001; 41(10-11): 1261-1275.

17 Euler T, Wässle H. Immunocytochemical identification of cone bipolar cells in the rat retina. J Comp Neurol 1995; 361(3): 461-478.

18 Humayun M, Propst R, de Juan Jr E, McCormick K, Hickingbotham D. BIpolar surface electrical stimulation of the vertebrate retina. Arch Ophthalmol 1994; 112(1): 110-116.

19 Humayun MS, de Juan Jr E, Dagnelie G, Greenberg RJ, Propst RH et al. VIsual perception elicited by electrical stimulation of retina in blind humans. Arch Ophthalmol 1996; 114(1): 40-46.

20 Humayun MS, De Juan Jr E, Weiland JD, Dagnelie G, Katona S, Greenberg R et al. Pattern electrical stimulation of the human retina. Vision Res 1999; 39(15): 2569-2576.

21 Liu W, McGucken E, Vitchiechom K, Clements M Juan Ed, Humayun M, (eds). Dual unit visual intraocular prosthesis. 1997 Proceedings of the 19th Annual International Conference of the IEEE; 1997; Engineering in Medicine and Biology Society, 1997.

22 Bird AC, Phillips RL, Hageman GS. Geographic atrophy: A histopathological assessment. JAMA Ophthalmol 2014; 132 (3): $338-345$.

23 Santos A, Humayun MS, de Juan Jr E, Greenburg RJ, Marsh MJ, Klock IB et al. Preservation of the inner retina in retinitis pigmentosa. A morphometric analysis. Arch Ophthalmol 1997; 115 (4): 511-515.

24 Majji AB, Humayun MS, Weiland JD, Suzuki S, D'Anna SA, de Juan JE. Long-term histological and electrophysiological results of an inactive epiretinal electrode array implantation in dogs. Invest Ophthalmol Vis Sci 1999; 40(9): 2073-2081.

25 Weiland JD, Humayun MS, Dagnelie G, de Juan Jr E, Greenberg RJ, Iliff NT. Understanding the origin of visual percepts elicited by electrical stimulation of the human retina. Graefes Arch Clin Exp Ophthalmol 1999; 237(12): 1007-1013.

26 Humayun MS, Prince M, de Juan JE, Barron Y, Moskowitz M, Klock IB et al. Morphometric analysis of the extramacular retina from postmortem eyes with retinitis pigmentosa. Invest Ophthalmol Vis Sci 1999; 40(1): 143-148.

27 Kim SY, Sadda S, Pearlman J, Humayun MS, de Juan EJ, Melia BM et al. Morphometric analysis of the macula in eyes with disciform age-related macular degeneration. Retina 2002; 22(4): 471-477.

28 Marc RE, Jones BW, Watt CB, Strettoi E. Neural remodeling in retinal degeneration. Prog Retin Eye Res 2003; 22(5): 607-655.

29 Sullivan R, Penfold P, Pow DV. Neuronal migration and glial remodeling in degenerating retinas of aged rats and in nonneovascular AMD. Invest Ophthalmol Vis Sci 2003; 44(2): 856-865.

30 Margalit E, Maia M, Weiland JD, Greenberg RJ, Fujii GY, Torres $\mathrm{G}$ et al. Retinal prosthesis for the blind. Surv Ophthalmol 2002; 47(4): 335-356.

31 Hornig R, Zehnder T, Velikay-Parel M, Laube T, Feucht M, Richard G. The IMI Retinal Implant System. In: Humayun MS, 
Weiland JD, Chader G, Greenbaum E (eds). Artificial Sight: Basic Research, Biomedical Engineering, and Clinical Advances. New York, NY. Springer: New York, 2007, pp111-128.

32 Richard G, Keserue M, Feucht M, Post N, Hornig R. Visual perception after long-term implantation of a retinal implant. Invest Ophthalmol Vis Sci 2008; 49(13): 1786.

33 Keserue M, Post N, Hornig R, Zeitz O, Richard G. Long term tolerability of the first wireless implant for electrical epiretinal stimulation. Invest Ophthalmol Vis Sci 2009; 50(13): 4226.

34 Keserü M, Feucht M, Bornfeld N, Laube T, Walter P, Rössler $\mathrm{G}$ et al. Acute electrical stimulation of the human retina with an epiretinal electrode array. Acta Ophthalmol 2012; 90(1): e1-e8.

35 Eckmiller R, Becker M, Hunermann R (eds). Towards a learning retina implant with epiretinal contacts. 1999 IEEE International Conference on Systems, Man, and Cybernetics, 1999 IEEE SMC '99 Conference Proceedings; 1999.

36 Hesse L, Schanze T, Wilms M, Eger M. Implantation of retina stimulation electrodes and recording of electrical stimulation responses in the visual cortex of the cat. Graefes Arch Clin Exp Ophthalmol 2000; 238(10): 840-845.

37 Peterman MC, Mehenti NZ, Bilbao KV, Lee CJ, Leng T, Noolandi $\mathrm{J}$ et al. The artificial synapse chip: a flexible retinal interface based on directed retinal cell growth and neurotransmitter stimulation. Artif Organs 2003; 27(11): 975-985.

38 Stieglitz T, Beutel H, Keller R, Blau C, Meyer JU (eds). Development of flexible stimulation devices for a retina implant system. 1997 Proceedings of the 19th Annual International Conference of the IEEE Engineering in Medicine and Biology Society; 1997.

39 Stieglitz T, Beutel H, Keller R, Meyer JU (eds). Integrative design and hybrid assembly of a flexible retina implant system. 1999 Proceedings of the First Joint [Engineering in Medicine and Biology, 1999 21st Annual Conference and the 1999 Annual Fall Meetring of the Biomedical Engineering Society] BMES/EMBS Conference; 1999.

40 Dowling J. Artificial human vision. Expert Rev Med Devices. 2005; 2(1): 73-85.

41 Chow AY, Pardue MT, Chow VY, Peyman GA, Chanping L, Perlman JI et al. Implantation of silicon chip microphotodiode arrays into the cat subretinal space. IEEE Trans Neural Syst Rehabil Eng 2001; 9(1): 86-95.

42 Chow AY, Chow VY, Packo KH, Pollack JS, Peyman GA, Schuchard R. THe artificial silicon retina microchip for the treatment of visionloss from retinitis pigmentosa. Arch Ophthalmol 2004; 122(4): 460-469.

43 Pardue MT, Phillips MJ, Yin H, Sippy BD, Webb-Wood S, Chow AY et al. Neuroprotective effect of subretinal implants in the RCS rat. Invest Ophthalmol Vis Sci 2005; 46(2): 674-682.

44 Pardue MT, Kim MK, Walker TA, Faulkner AE, Chow AY, Ciavatta VT. Neuroprotective dose response in RCS rats implanted with microphotodiode arrays. Adv Exp Med Biol 2012; 723: 115-120.

45 Palanker D, Vankov A, Huie P, Baccus S. Design of a highresolution optoelectronic retinal prosthesis. J Neural Eng 2005; 2(1): S105-S120.

46 Zrenner E, Bartz-Schmidt KU, Benav H, Besch D, Bruckmann A, Gabel VP et al. Subretinal electronic chips allow blind patients to read letters and combine them to words. Proc Biol Sci 2011; 278(1711): 1489-1497.

47 Wilke R, Gabel VP, Sachs H, Schmidt KUB, Gekeler F, Besch D et al. Spatial resolution and perception of patterns mediated by a subretinal 16-electrode array in patients blinded by hereditary retinal dystrophies. Invest Ophthalmol Vis Sci 2011; 52(8): 5995-6003.

48 Stingl K, Bartz-Schmidt KU, Besch D, Braun A, Bruckmann A, Gekeler F et al. Artificial vision with wirelessly powered subretinal electronic implant alpha-IMS. Proc Biol Sci 2013; 280(1757): 20130077.

49 Chuang AT, Margo CE, Greenberg PB. Retinal implants: a systematic review. Br J Ophthalmol 2014; 98(7): 852-856.

50 Luo YHL, da Cruz L. The Argus II Retinal Prosthesis System. Prog Retin Eye Res 2016; 50: 89-107.

51 Humayun MS, Dorn JD, Da Cruz L, Dagnelie G, Sahel JA, Stanga PE et al. Interim results from the international trial of second sight's visual prosthesis. Ophthalmology 2012; 119(4): 779-788.

52 Stanga PE Jr JAS, daCruz L, Hafezi F, Merlini F, Coley B et al. Patients blinded by outer retinal dystrophies are able to perceive simultaneous colors using the Argus II Retinal Prosthesis System. Invest Ophthalmol Vis Sci 2012; 53(14): 6952.

53 Stanga PE, Hafezi F, Sahel JA, daCruz L, Merlini F, Coley B et al. Patients blinded by outer retinal dystrophies are able to perceive color using the argustm ii retinal prosthesis system. Invest Ophthalmol Vis Sci 2011; 52(14): 4949.

54 Stanga PE, Coley B, Merlini F, Biswas S, Turner G, Greenberg R. Initial word recognition results with the ArgusTM II retinal prosthesis. Invest Ophthalmol Vis Sci 2010; 51(13): 426.

55 Stanga P, Sahel J, Mohand-Said S, daCruz L, Caspi A, Merlini F et al. Face detection using the Argus II Retinal Prosthesis System. Invest Ophthalmol Vis Sci 2010; 54(15): 1766.

56 Handa J Safety and Performance Results of the Argus II Retinal Prosthesis System Five Years Post-Implant. 39th Annual Macula Society Meeting 2016.

57 da Cruz L, Dorn JD, Humayun MS, Dagnelie G, Handa J, Barale P-O et al. Five-year safety and performance results from the Argus II Retinal Prosthesis System clinical trial. Ophthalmology 2016; 123(10): 2248-2254.

58 Ho AC, Humayun MS, Dorn JD, Da Cruz L, Dagnelie G, Handa J et al. Long-term results from an epiretinal prosthesis to restore sight to the blind. Ophthalmology 2015; 122(8): 1547-1554.

59 Koitschev A, Stingl K, Bartz-Schmidt KU, Braun A, Gekeler F, Greppmaier U et al. Extraocular surgical approach for placement of subretinal implants in blind patients: lessons from cochlear-implants. J Ophthalmol 2015; 2015: 842518.

60 Stingl K, Bartz-Schmidt KU, Besch D, Chee CK, Cottriall CL, Gekeler F et al. Subretinal visual implant Alpha IMSclinical trial interim report. Vision Res 2015; 111(Pt B): 149-160.

61 Kitiratschky VB, Stingl K, Wilhelm B, Peters T, Besch D, Sachs $\mathrm{H}$ et al. Safety evaluation of "retina implant alpha IMS"-a prospective clinical trial. Graefes Arch Clin Exp Ophthalmol 2015; 253(3): 381-387.

62 Schatz A, Röck T, Naycheva L, Willmann G, Wilhelm B, Peters T et al. Transcorneal electrical stimulation for patients with retinitis pigmentosa: a Prospective, Randomized, Sham-Controlled Exploratory Study. Invest Ophthalmol Vis Sci 2011; 52(7): 4485-4496.

63 Stronks HC, Dagnelie G. The functional performance of the Argus II retinal prosthesis. Expert Rev Med Devices 2014; 11(1): 23-30. 
64 Vaidya A, Borgonovi E, Taylor RS, Sahel JA, Rizzo S, Stanga PE et al. The cost-effectiveness of the Argus II retinal prosthesis in Retinitis Pigmentosa patients. BMC Ophthalmol 2014; 14: 49

65 Brower A. Is it time to take a harder look at the QALY? Biotechnol Healthc 2008; 5(3): 47-48.

66 Miller A. Retinal implant system delivers limited sight to some blind people. CMAJ 2013; 185(14): E659-E660.

67 Roessler G, Laube T, Brockmann C, Kirschkamp T, Mazinani B, Menzel-Severing J et al. Angiographic findings following tack fixation of a wireless epiretinal retina implant device in blind RP patients. Graefes Arch Clin Exp Ophthalmol 2011; 249(9): 1281-1286.
68 Menzel-Severing J, Laube T, Brockmann C, Bornfeld N, Mokwa W, Mazinani B et al. Implantation and explantation of an active epiretinal visual prosthesis: 2-year follow-up data from the EPIRET3 prospective clinical trial. Eye (Lond) 2012; 26(4): 501-509.

69 Rizzo IJF. Update on retinal prosthetic research: The Boston retinal implant project. J Neuroophthalmol 2011; 31(2): 160-168.

70 Kelly SK, Shire DB, Chen J, Doyle P, Gingerich MD, Cogan SF et al. Communication and control system for a 15-channel hermetic retinal prosthesis. Biomed Signal Process Control 2011; 6(4): 356-363. 